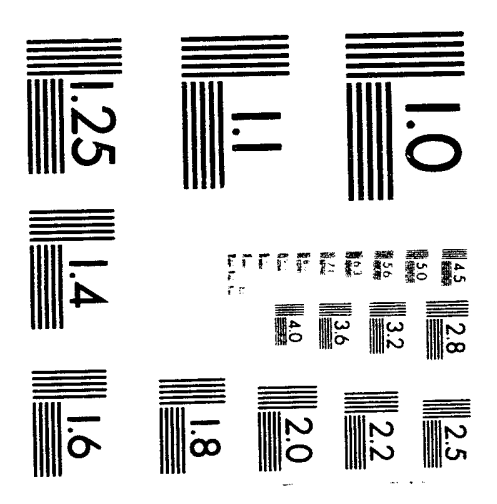



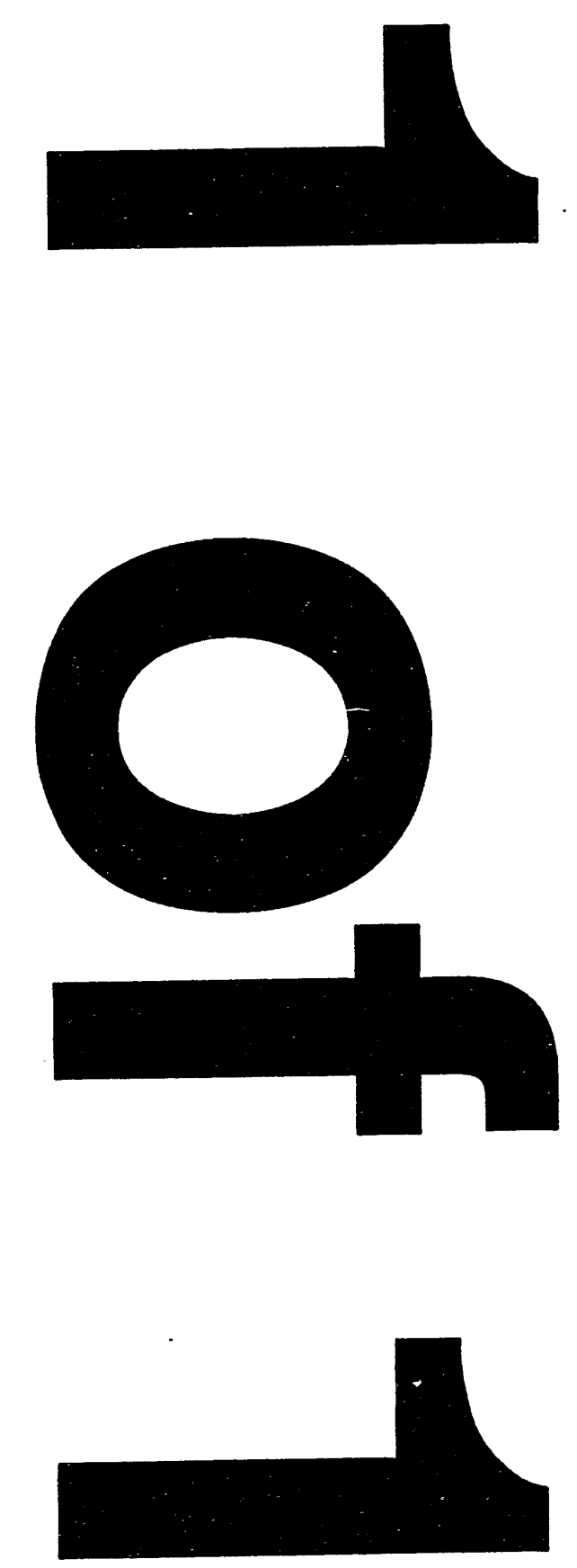


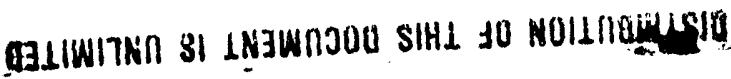
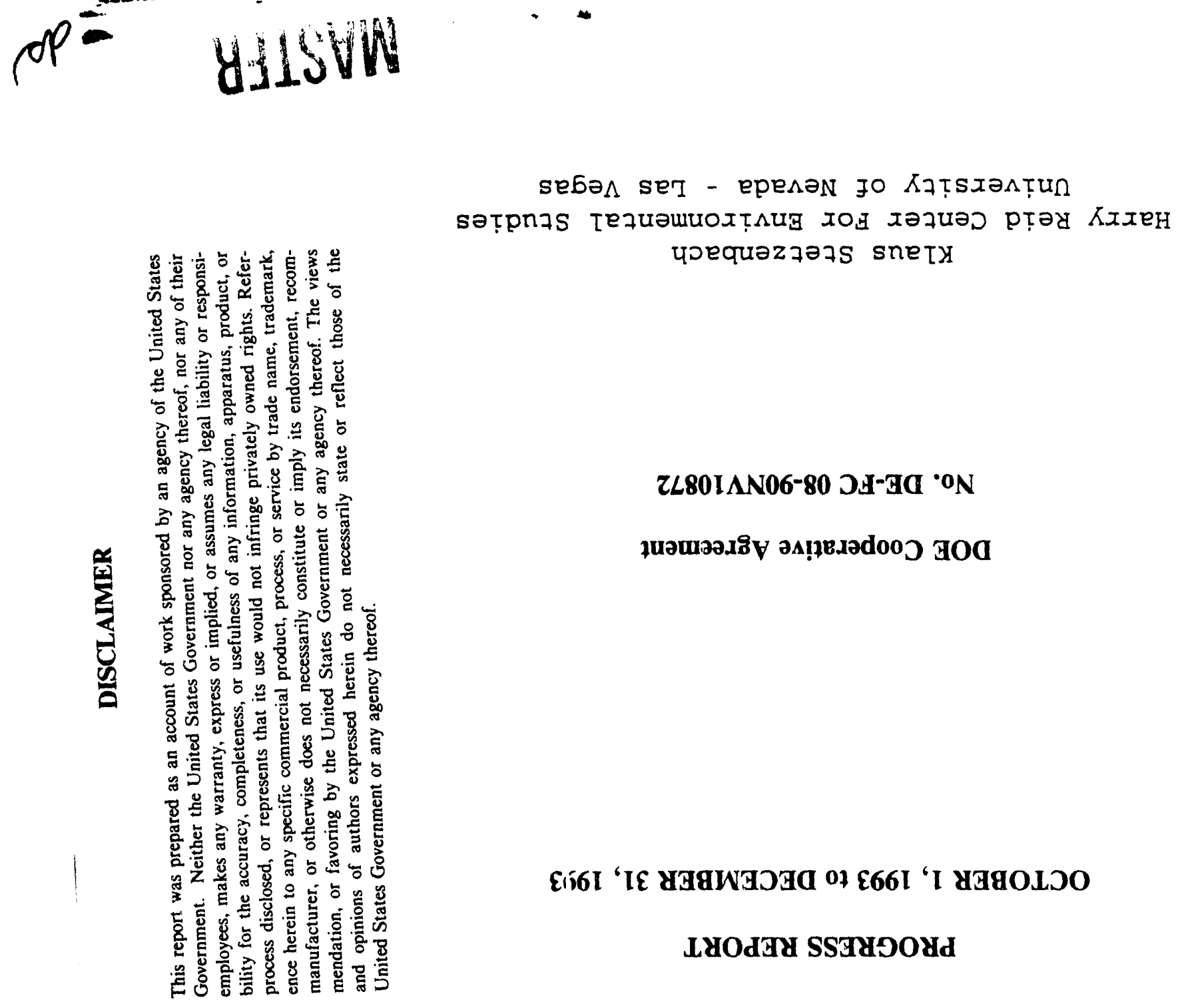

ZL80IAN06-80 OH-Ga '0N

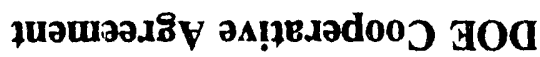

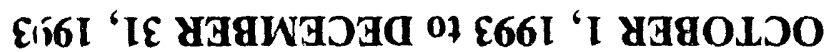

LyOd'A SSTYOOYd

MANIS NOILVZIYALDVYVHD GLIS

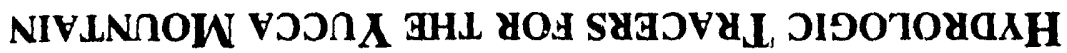

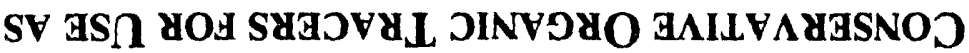

HO NOILVZI\&GLDVYVHD ANV NOILVOIHILNGAI

$1 b 1-C(80) / \lambda N / \exists O C$ 
During this quarter our main effort was directed towards rewriting our quality assurance program in preparation for a review and audit by the USGS. However, due to budget constraints the review and audit were not carried out. The tracer $Q A$ plan and standard operating procedures (SOPS) were revised and copies are included with this report.

In addition to losing the trained personnel that had been working on the tracer program (see July - September 1993 report)we encountered both instrumental and sample problems. The instrumental problems have been corrected with the addition of new integration and sample control software. The sample problem was an unexplained peak in the chromatograms of the tracers being tested in the light tuff. We were not able to correct this situation and these experiments are going to be done again during the next quarter. 


\title{
UNIVERSITY OF NEVADA, LAS VEGAS
}

Harry Reid Center for Environmental Studies

\section{QUALITY ASSURANCE PROJECT PLAN}

\author{
Identification and Characterization of \\ Conservative Organic Tracers for Use as Hydrologi Tracers \\ For the Yucca Mountain Site Characterization Project
}

\section{Cooperative Agreement DE-FC08-90NV10872}

Klaus J. Stetzenbach

Project Manager

Harry Reid Center for Environmental Stu: ies

University of Nevada, Las Vegas

Las Vegas, Nevada 89154-4009

\section{SIGNATURES OF APPROVAL}

Comsomiecusole

HRC QQ \$taff

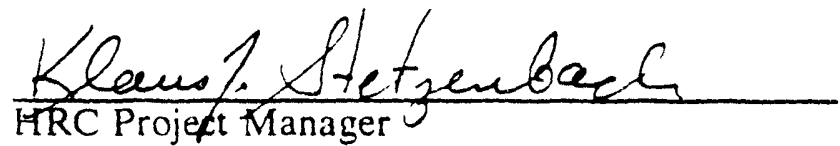

$\frac{1-10-94}{\text { Date }}$

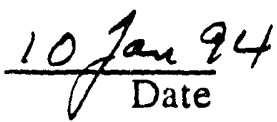

- Revisions are indicated by a vertical line in the right margin. 
Tracer.QAP

Revision No. $1^{*}$

Date: $12 / 13 / 93$

Page 2 of 38

\section{CONTENTS}

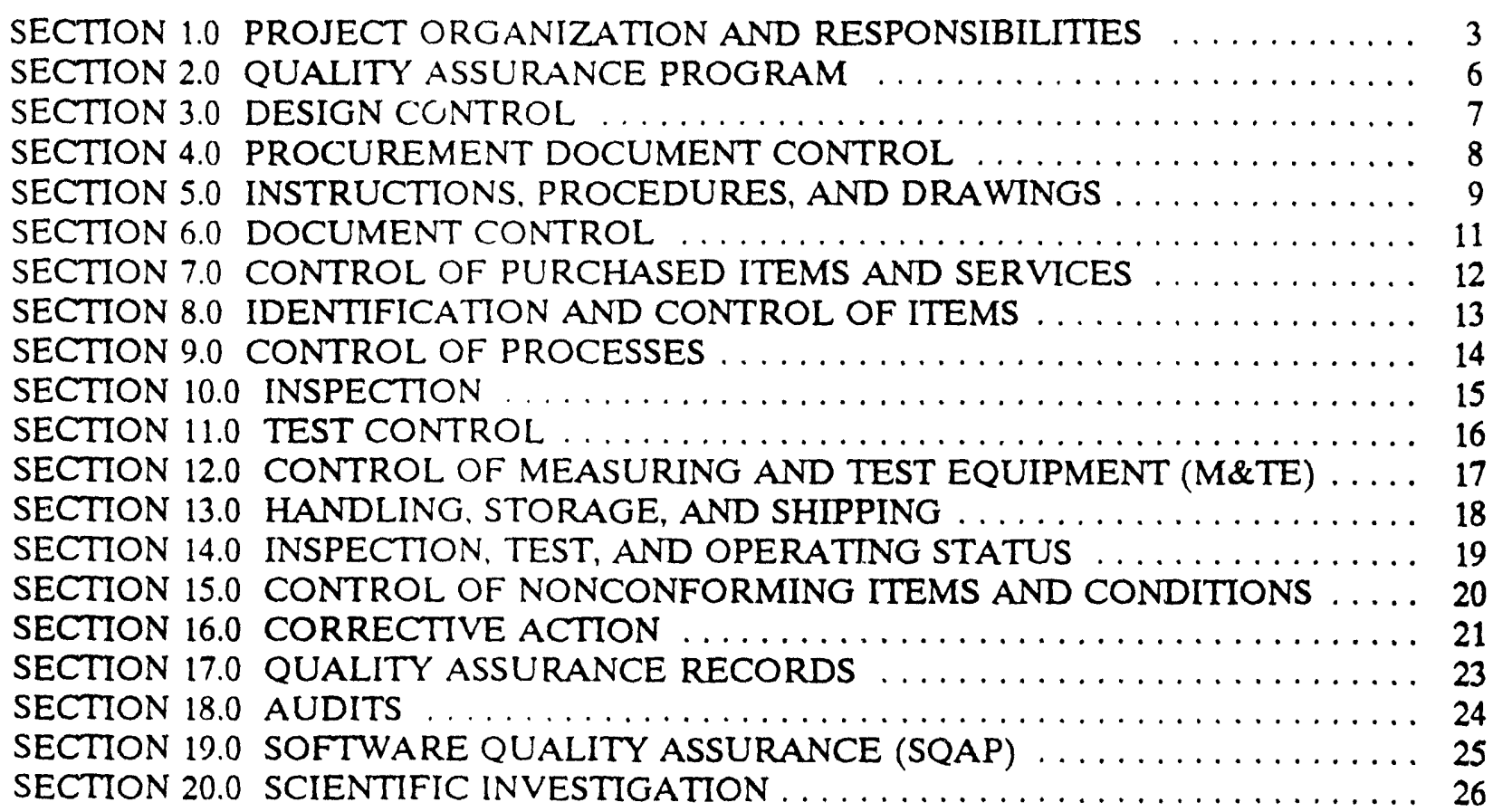

- Revisions are indicated by a vertical line in the right margin. 
Tracer.QAP

Revision No. $1^{*}$

Date: $12 / 13 / 93$

Page 3 of 38

\section{SECTION 1.0}

\section{PROJECT ORGANIZATION AND RESPONSIBILITIES}

\subsection{PROJECT RESPONSIBILITIES (Figure 1)}

The Project Manager has the overall project technical lead and is also responsible for document control, stop work, and administrative and financial matter:. The investigators will be responsible for tasks as assigned by the project manager.

The individual investigator and/or technician is responsible for the quality of the results generated from his or her task. For cases where an investigator or project manager act as one, the individual assumes the responsibilities described for these positions. (Follow all QA requirements specified for the investigator in the QAP, the SOPs [as defined in 2.1], and the QAPP.)

\subsection{UNLV QUALITY ASSURANCE STAFF}

The Quality Assurance (QA) staff serves in a consulting, verification, and assessment capacity and is available to all project personnel in QA matters. The HRC QA staff performs independently of the Tracer Project reporting directly to the directcr.

- Helping to assure the correct application of appropriate QA requirements by line management through review of the Q; iPP, QA Project Plan (QAP), and the standard operating procedures (SOPs);

- Monitoring the QA program through overview activities that, as a minimum, include internal assessments and reviews.

\subsection{COMMUNICATIONS}

Routes of communication basically follow the organizational scheme with project information flowing freely within HRC and formal communications moving through and between investigators and the project manager. Formal external communication travels from the project manager or his designee to the client or other outside entity.

- Revisions are indicated by a vertical line in the right margin. 
Tracer.QAP

Revision No. $1^{*}$

Date: $12 / 13 / 93$

Page 4 of 38

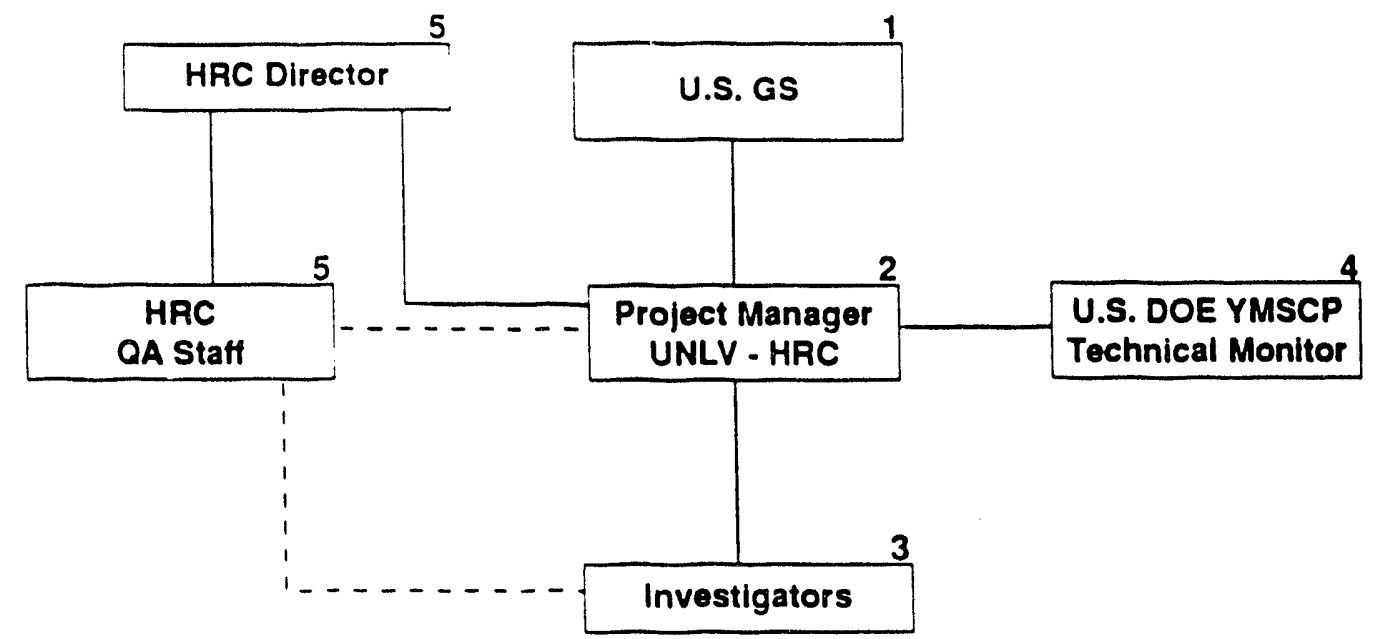

Technical Direction

1 Sampling

2 Project design/QAreport generation

3 Analytical/data reduction

4 Ultimate project oversight funding resources

5 Internal QA management

- Revisions are indicated by a vertical line in the right margin. 
Tracer.QAP

Revision No. $1^{*}$

Date: $12 / 13 / 93$

Page 5 of 38

\subsection{STOP WORK PROVISION}

The project manager is responsible to stop work on the Tracer Project when it is determined that QA documents are not being followed or data quality is out of control. The project manager will see that nonconformances or out-of-control processes and corrective actions are documented. The procedure for the stop work process is contained in the attached SOP. The HRC QA staff will verify that corrective action has been taken.

- Revisions are indicated by a vertical line in the right margin. 


\section{SECTION 2.0}

\section{QUALITY ASSURANCE PROGRAM}

\section{$2.1 \quad$ POLICY}

The following policies have been implemented for the Tracer Project:

* This project has a QAP. No quality-affecting work will be performed before acceptance of this document.

* Standard operating procedures (called standard operating procedures, SOPs in this document) are prepared for routine tasks. Non-routine activities are documented in scientific notebooks.

* Overview activities of the Tracer Project may be performed.

* All data generated by the Tracer Project, for which official written notification of the status of "activity affecting quality" has been received by the project manager from the U.S. DOE, are supported by QA criteria and documentation to ensure that all data collected, stored, reported, or used by the Tracer Project are scientifically sound, defensible, and of adequately known precision and accuracy.

\subsection{QA DOCUMENTS}

The Tracer Project implements the requirements of the U.S. DOE Yucca Mountain QA | Program, by the establishment of this and other task-oriented QAPs and all SOPs detailed implementing procedures, and scientific notebooks.

\subsection{DELIVERABLES}

The Tracer Project is performed using appropriate conditions and instrumentation by personnel with suitable backgrounds and education to provide an acceptable deliverable.

\subsection{PERSONNEL}

Qualified personnel are utilized on all levels for the tracer task. Resumés are on file in the HRC office and made available to authorized personnel for review.

- Revisions are indicated by a vertical line in the right margin. 
Tracer.QAP

Revision No. 1*

Date: 12/13/93

Page 7 of 38

\section{SECTION 3.0 \\ DESIGN CONTROL}

The U.S. DOE has not issued a technical directive for this project to fulfill the QA requirement for "design control."

- Revisions are indicated by a vertical line in the right margin. 


\section{SECTION 4.0}

\section{PROCUREMENT DOCUMENT CONTROL}

The Tracer Project will not perform procurement functions.

- Revisions are indicated by a vertical line in the right margin. 
SECTION 5.0

\section{INSTRLCTIONS, PROCEDURES, AND DRAWINGS}

\subsection{QUALITY ASSURANCE PROJECT PLAN (QAP)}

The project manager sees that the QAP is written, reviewed, approved, and issued. This I includes document control. The document is submitted to his DOE counterpart for review. The HRC QA staff shall review and approve the QAP also. The project manager will also determine when the QAP needs revision.

\subsection{Standard operating procedures (SOPs)}

SOPs are used for those procedures that the project manager deems routine. SOPs for the following activities are followed for the Tracer Project:

High pressure liquid chromatograph operation

Test Procedures

Sartorius $2+32$

Scientific Notebooks

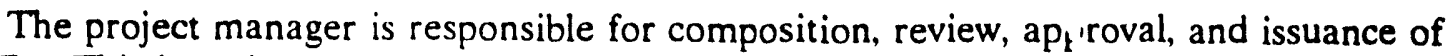
the SOPs. This includes document control.

\subsection{DETAILED IMPLEMENTING PROCEDURES (DIPs)}

The project manager is responsible for the development of DIPs, including assurance that the appropriate persons prepare, review, approve, and issue DII's. DIPs for the following activity are followed for the Tracer Project:

\section{Stop Work}

\subsection{SCIENTIFIC NOTEBOOKS}

The project manager deems the following activities to be non-routine: preparation of standards and solvents, sample analyses, methods changes and developments, observations and results, sampling details, instrument parameters, and other conditions and occurrences that are not predictable but important to the outcome of the project. Experimental findings and details of this project are recorded in scientific notebooks obtained from the UNLV Central Stores or equivalent using the scientific notebook SOP. These are hardcover permanently bound volumes. In every case where findings and data are recorded, the date and the investigator's initials must be recorded with the observation. Records shall be in ink and deletions shall be made by a

- Revisions are indicated by a vertical line in the right margin. 
Tracer.QAP Revision No. * $^{*}$

Date: $12 / 13 / 93$

Page 10 of 38

single line-through. Deletions and changes are accompanied by the initials of the individual making the change and the date of the change. The use of correction fluid and pencil is prohibited in notebooks and on data sheets. In cases where observations were recorded on extraneous paper, that paper shall be permanently affixed to the notebook or sheet, rather than transferred. to avoid errors.

- Revisions are indicated by a vertical line in the right margin. 
Tracer.QAP

Revision No. $1^{*}$

Date: $12 / 13 / 93$

Page 11 of 38

\section{SECTION 6.0 \\ DOCUMENT CONTROL}

All QA plans, SOPs, and DIPs developed for this project have the following identifying plate in the upper right-hand corner of each page.

Word-processing file name

Revision No.

Date:

Page _ of

"Revision number" is the numeric representation of the approved protocol revision. The original unrevised version is numbered 0 . The "Date" indicates the date of the revision.

In all cases, employees possess only the most recent revision o: a protocol. A copy of each obsolete revision is archived by the QA Officer for reference purposes. documents.

The Project Manager is responsible to see that personnel use only the most current

\footnotetext{
- Revisions are indicated by a vertical line in the right margin.
} 
Tracer.QAP

Revision No. $1^{*}$

Date: $12 / 13 / 93$

Page 12 of 38

SECTION 7.0

CONTROL OF PURCHASED ITEMS AND SERVICES

Purchases of material, equipment, and services conform to UNLV procurement documents (Title 4, Chapter 3).

\subsection{GENERAL}

Purchases of materials and equipment are accomplished as in NQA-1 Section 7S-1 subsection 10 for commercial grade materials. [Note: NQA-1 definition of commercial grade materials is an item that is not subject to design or specification requirements that are unique to nuclear facilities; used in applications other than nuclear facilities; and is to be ordered from the manufacturer/supplier on the basis of specifications set forth in the manufacturer's published product description (for example, catalog).]

\footnotetext{
- Revisions are indicated by a vertical line in the right margin.
} 


\section{SECTION 8.0}

\section{IDENTIFICATION AND CONTROL OF ITEMS}

The requirements of this section apply to engineered items and do not apply to scientific investigations. Identification and control of samples and data are addressed in Section 20, Scientific Investigations.

\footnotetext{
- Revisions are indicated by a vertical line in the right margin.
} 
Tracer.QAP

Revision No. $1^{*}$

Date: $12 / 13 / 93$

Page 14 of 38

SECTION 9.0

CONTROL OF PROCESSES

The activities associatied with the Tracer Project do not include processes that need to be controlled in the sense of this criterion.

- Revisions are indicated by a vertical line in the right margin. 
Tracer.QAP

Revision No. $1^{*}$

Date: $12 / 13 / 93$

Page 15 of 38

\section{SECTION 10.0 \\ INSPECTION}

The activities associated with the Tracer Project do not require verification of conformance against standards or specified requirements; therefore, this criterion does not apply to this QAP.

- Revisions are indicated by a vertical line in the right margin. 
Tracer.QAP

Revision No. 1*

Date: $12 / 13 / 93$

Page 16 of 38

\section{SECTION 11.0}

\section{TEST CONTROL}

The activities associated with this project do not include tests that need to be controlled in the sense of this criterion.

- Revisions are indicated by a vertical line in the right margin. 


\section{SECTION 12.0}

\section{CONTROL OF MEASURING AND TEST EQUIPMENT (M\&TE)}

\subsection{CALIBRATION ${ }^{1}$ AND MAINTENANCE}

The high performance liquid chromatograph (HPLC) and the HPLC-mass spectrometer (HPLC-MS) are calibrated prior to each analysis using a 3-or more-point external standard curve. Tuning and calibration of the mass spectrometer will be done prior to each analysis and will be documented in the scientitic notebook.

\subsection{STANDARDS}

The preparation and use of standards is recorded as developed in scientific notebooks.

\subsection{ACCEPTANCE CRITERIA}

The correlation coefficient for the calibration curve, must be equal to or exceed the value specified in the SOP for that instrument. For every ten samples a mid-range standard check will be performed. The response of the standard must be within $10 \%$ of the value determined during initial calibration for analyses to continue. The mid-range standard check provides verification that the instrument maintains calibration throug' out the analysis.

1 A complex and sensitive analytical system such as an HPLC or HPLC-MS must be shown to be stable and optimized prior to sample analysis.

- Revisions are indicated by a vertical line in the right margin. 
Tracer.QAP

Revision No. $1^{*}$

Date: $12 / 13 / 93$

Page 18 of 38

\section{SECTION 13.0}

\section{HANDLING, STORAGE, AND SHIPPING}

Samples will be handled. stored, and labelled in accordance with the provisions of the applicable SOPs. All samples will be maintained in the laboratory and during transportation under conditions appropriate to the experimental and analytical conditions.

- Revisions are indicated by a vertical line in the right margin. 
Tracer.QAP

Revision No. $1^{*}$

Date: 12/13/93

Page 19 of 38

SECTION 14.0

INSPECTION, TEST, AND OPERATING STATUS

The requirements of this section apply to engineered items and do not apply to scientific investigations. The requirements of this criterion do not apply to this QAP.

- Revisions are indicated by a vertical line in the right margin. 
Tracer.QAP

Revision No. $1^{*}$

Date: $12 / 13 / 93$

Page 20 of 38

\section{SECTION 15.0}

\section{CONTROL OF NONCONFORMING ITEMS AN!D CONDITIONS}

The provisions of NQA-1 Basic Requirement 15 and Supplement $15 \mathrm{~S}-1$ shall apply to quality-related items or activities under the control of HRC.

Procedures and responsibilities for handling nonconformances will be specified on a taskby-task basis. The initiations for the following steps will be outlined with assigned roles and responsibilities at the task level. When a nonconforming item or condition is identified, it shall be documented, tracked, segregated. logged, evaluated, reviewed, verified, reported, and dispositioned as appropriate.

Examples of nonconforming items are parts, materials, components, and hardware that do not comply with documented requirements of QAPs. TDPs, etc. The disposition of a nonconforming item, which may be use-as-is, repair, rework, or reject, will be documented. Examples of nonconforming conditions (programmatic deficiencies) are failures to comply with procedures, plans, drawings, instructions, regulations, or other established requirements.

- Revisions are indicated by a vertical line in the right margin. 
SECTION 16.0

CORRECTIVE ACTION

\subsection{DOCUMENTATION}

Any significant condition requiring corrective action and the resulting resolution shall be documented on a CAR form (figure 2).

\subsection{RESPONSE TO SIGNIFICANT CONDITIONS ADVERSE TO QUALITY}

Examples of activities where a CAR may initiate are:

* Performance audits

* Systems audits

* Interlab/Intertield Studies

* Failure to document a deviation from this QAP, or a project SOP.

- Revisions are indicated by a vertical line in the right margin. 


\section{CORRECTIVE ACTION REPORT}

\begin{tabular}{l|l|l}
\hline \multicolumn{2}{|c|}{ INTIMTOR } \\
\hline Initiator: & CAR Date: & CAR No. \\
\hline Responsible Organzacion: & Location: & $\begin{array}{l}\text { Stop Work } \\
\text { Yes } D \text { No }\end{array}$ \\
\hline Specitication Requrements: & &
\end{tabular}

\section{Deficiency:}

Technical Justification:

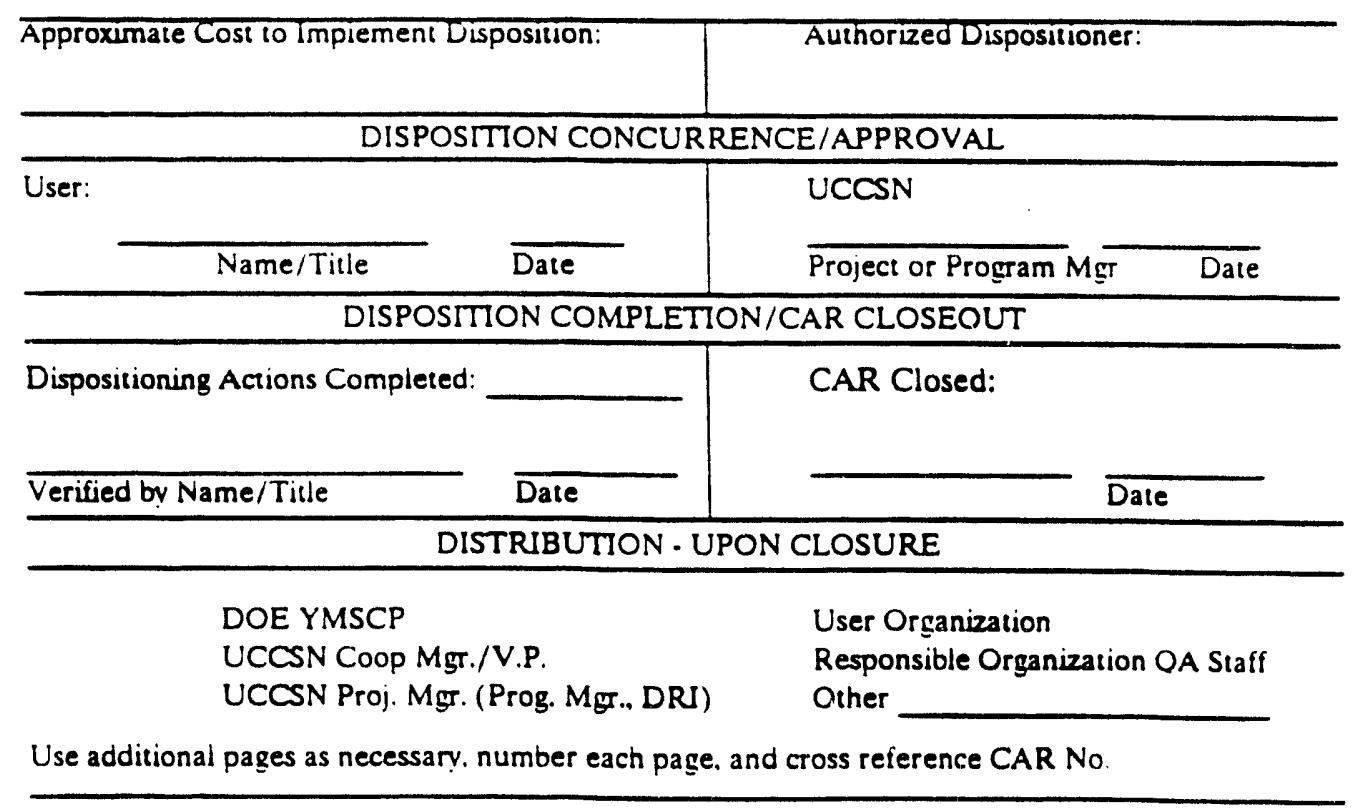

- Revisions are indicated by a vertical line in the right margin. 


\section{QUALITY ASSLIDANCE RECORDS}

All reproducible data produced and/or processed will be maintained in duplicate storage until transmitted to the YMSCF Project Office as a deliverable. One-of-a-kind records will be sent to the YMSCP Project Office as soon as each becomes a QA record. Records that furnish documentary evidence of quality and are prepared and maintained by HRC for this project are specified below. Records shall be distributed, handled, and controlled for a minimum of three years at HRC. Upon termination of the project or of a task, the following records will be submitted to the QA officer who will see that they are stored as described in the chemistry laboratory data management system.

Research data records shall be stored in analysts' files until su th time that data are transferred to the HR.C Chemistry Division Data Management Systen and/or the Y'MSCP. Data records will be transferred to the data management system or YMSCP at the time that personnel complete that segment of research and no longer require immediate access to the data. Other records are generally stored with personnel as indicated below for the duration of the project.

\section{QA Office Files}

QA Program Plan

QA Project Plan

SOPs

Audit Files

HRC Chemistry Lahoratory Data Management System

Data reports

Verified and validated raw data-hardcopy

Data verification/validation records

Audit Files

Inactive Scientific Notebooks

HRC Accounts Specialist

Procurements/purchases

SOPs should be available at each instrument or work area (for which they will be written), so that operators will have them available for reference while working on the Tracer Project.

\footnotetext{
- Revisions are indicated by a vertical line in the right margin.
} 
Tracer.QAP

Revision No. $1^{*}$

Date: $12 / 13 / 93$

Page 24 of 38

A completed record is a jocument that will either receive no more entries, or whose revision normally would consist of the reissue of the document and is signed and dated by the originator. and as applicable by other personnel authorized to approve the document.

- Revisions are indicated by a vertical line in the right margin. 


\section{SECTION 18.0}

\section{AUDITS}

\subsection{AUDIT SCHEDULES}

At this time no audit schedules have been established. However, the general plan is that the HRC QA officer may pertorm systems audits of HRC projects and provide materials for performance audits (if available). Performance audit results (review of data and any QC sample results) will be discussed at systems audits. Systems audits may provide an objective evaluation of quality-related practices. procedures. instructions, activities, and items, including the review of documents and reccrds, to insure that the QA Program is effective and implemented properly.

Results of audits performed by the HRC QA staff are to be reported to the project manager with copies to the HRC management. Corrective action shall be accomplished as addressed in Section 16.

\footnotetext{
- Revisions are indicated by a vertical line in the right margin.
} 


\section{SECTION 19.0}

\section{SOFTWARE QUALITY ASSURANCE (SQAP)}

Based on the specificitions and definitions for this criterion in the Quality Assurance Requirements Description Docment, an SQAP is not required for the Tracer Project. No software is developed by this project.

\footnotetext{
- Revisions are indicated by a vertical line in the right margin.
} 
Tracer.QAP

Revision No. $1^{*}$

Date: $12 / 13 / 93$

Page 27 of 38

SECTION 20.0

SCIENTIFIC INVESTIGATION

\subsection{PLANNING}

\subsubsection{Project Description}

Ground-water tracers are solutes dissolved in or carried by ground water to delineate flow pathways. Tracers provide information on direction and speed of water movement and on contaminants that might be conveved by the water. Tracers can also be used to measure effective porosity, hydraulic conductivity, dispersivity, and solute distribution coefficients. Tracers can be naturally-occurring compounds or elements or they ca 1 be completely foreign to the environment. The latter is generally preferred. For most applications, tracers should be conservative, that is, move at the same rate as the water and not sorb to aquifer materials.

Tracers must have a number of properties to be functional. Regardless of the desired properties, the chemical and physical behavior of a tracer in ground water and the porous medium under study must be understood. Good estimates of tracer sehavior can be obtained from laboratory studies. For the purposes of the Yucca Mountain C-well complex conservative tracer study, the tracers should have the following properties:

1) Must be water soluble.

2) Should not sorb on the aquifer material (i.e., be conservative, non-reactive).

3) Should be chemically and biologically stable for the duration of the test.

4) Should be foreign to the Yucca Mountain environme:it.

5) Should have excellent analytical sensitivity.

6) Should be non-toxic. Its degradation products will be metabolized by aerobic bacteria to $\mathrm{F}$ and $\mathrm{CO}_{2}$.

The studies outlined in this plan will address the above stated tracer properties with analytical method development, static sorption and degradation studies, anc column transport studies. Mutagenicity tests will be performed on promising candidates.

The tracers that will be used for these experiments are fluorinated organic acids and other organic compounds that have the chemical and biological stability necessary to be effective in the Yucca Mountain environment. Special emphasis will be placed on compounds that fluoresce or have very large ultraviolet absorption coefficients tor very high analytical sensitivity.

- Revisions are indicated by a vertical line in the right margin. 
Tracer.QAP

Revision No. $1^{*}$

Date: $12 / 13 / 93$

Page 28 of 38

The column tests (lask $\downarrow$ ) will be conducted relative to bromide. Bromide will also be used by other investigators as a standard tracer and will allow comparisons to be made of relative sorption rates between experiments.

20.1.1.1 Statement of Work

The purpose of this work is to identify and characterize candidate conservative organic tracers for use as hydrologic tracers for experiments to be conducted at the $C$-well complex.

General Outline of Tasks as received from the Department of Energy:

1) Identify candidate tracers for use as conservative tracers.

2) Conduct analytical chemical evaluation of promising candidate tracers by evaluating detection limits with respect to the Yucca Mountain environment.

3) Conduct hatch tests on promising candidate tracers to evaluate suitability using a mass balance approach with consideration for time dependence.

4) Conduct column tests on promising candidate tracers with both crushed and intact core material and provide qualitative evaluations relative to bromide.

5) Conduct tests for degradation of candidate tracer compounds due to microbial action and chemical reactions under the environmental conditions anticipated at the C-well complex. Provide evidence for non-toxicity.

(1) Prepare an appropriate level quality assurance program.

7) Report recommendations for field application of conservative organic tracers for hydrologic testing.

20.1.1.2 Approach

To successfully select a tracer or a suite of tracers for a specific application tequires estimates of the length of time that tracers will reside in the subsurface and the volume of water that must be traced. These estimates will be obtained from the USGS.

The identification of candidate conservative tracers (task 1) will be performed through a literature search and from previous experience with ground-water tracers (1-5). Candidate tracers should meet as many of the criteria listed in the project description (Section 1.0) as possible. Under consideration at this time are fluorinated salicylic acids, fluorinated benzoic acids, tluorinated cinnamic acids, and fluorinated aliphatic acids.

- Revisions are indicated by a vertical line in the right margin. 
It is anticipated that a significant portion of the tracer sample analysis during an actual test will be conducted in the field. For this reason the analytical procedures should be kept as simple as possible and be done with instrumentation rugged enough to be used in the field. An instrumental method that meets these requirements and is most convenient for analyzing water samples is High Performance Liquid Chromatography (HPLC)"specifically, reversed phase HPLC. Reversed phase HPLC ullows the tracer samples to be injected directly with no sample pretreatment other than filtration. The method can be used with fluorescence and ultraviolet absorption detectors and can be very sensitive with the appropriate tracers. For this reason, the major analytical efforts (task 2) will be directed towards the use of this method. The detection limits will be evaluated with fluids, either real or formulated to simulate the waters in the area of the $C$-well complex. Tracers that do not have suitable chromophores will be analyzed by HPLC-mass spectrometry (HPLC.MS). This technique will also be used for the identification of tracer degradation products, if necessary.

The initial experiments to evaluate the suitability of the candidate tracers (task 3 ) will be batch stability tests that will test for both, but not differentiate betwet $n$, chemical reactions, including sorption and biodegradation. The batch tests will be conducted with two water solutions and a number of water and soil mixtures. One of the water solutions will be distilled water for control purposes. The other water-only solution will be water obtained from the J-13 well.

This QAP covers only the tracer tests at the C-well complex, a id only the chemical composition of that water is addressed. The C-wells are close enough to J-13 to assume that the composition of the water is essentially the same. The State of Nevada Dept. of Environmental Protection permit assumes the waters are the same. The tracers are inert and stable and will not behave differently in waters with minor variations in their chemical content.

The water/soil mixtures will be made up of crushed tuff frorti outcropping of tuff that will be in the tracer test horizon. The number and types of tuff will be determined with the aid of U.S. DOE geologists. The concentration of the tracers used in these tests will be chosen for high analytical precision so that small reductions in concentration will be easy to recognize. The water and the tulf will be in a 1:1 weight ratio. Candidate tracers that show no significant reduction in concentration after 30 days will be used for further testing.

Since field tracer test chemicals and their degradation products may remain in the ground water for many years, it would be beneficial to the overall study if the laboratory tests would continue until the completion of the Yucca Mountain site characterization project to observe long- term tracer stability and identify degradation products.

Column tests (task 4 ) will be conducted on all tracers that appear to be stable and conservative under conditions expected at the C-well complex. The column tests for this study will attempt to follow the procedures and methods used by Dr. Robert Bowman (1989). The

Revisions are indicated by a vertical line in the right margin. 
Tracer.QAP

Revision No. $1^{*}$

Date: $12 / 13 / 93$

Page 30 of 38

columns will be constructed of plexiglas, about $30 \mathrm{~cm}$ in length and $5 \mathrm{~cm}$ in outside diameter, and will be packed with crushed core material obtained from the $\mathrm{C}$-well corings or other suitable locations from the Yucca Mountain area. The columns will be packed to an approximate bulk density of 1.5 grams per cubic centimeter. Solutions containing the tracer will be made of filtered water obtained from the J-13 wells. The concentration of tracer will be based upon results obtained from the batch studies. The linear flow rates through the column will depend upon the pumping system and the estimated linear velocity of the tracers in an actual test. A continuous UV or tluorescence monitor will be connected for real time analysis of the tracer solution as it comes off the column. The effluent from the continuous monitor may be directed to a fraction collector for later analysis by HPLC or other appropriate analytical

instrumentation. Pulse injections of tracer, rather than a continuous infusion of traced solution, will be used as this method is more representative of the actual tracer experiments and is more convenient for repetitive (QA purposes) experiments. In addition to the tracer of interest, bromide will be tested on every column as a reference tracer. The concentration of tracer and the linear velocities of the solution will be varied to determine the effects of kinetics and to determine the capacity of the aquifer material.

Experiments with intact core will be performed in a manner similar to the one described above, but with the following qualifiers. The size of the column and therefore the size of the piece of core used will depend on the hy uraulic conductivity of the core. Since the hydraulic conductivity of tuff may be as low as $10^{-12} \mathrm{~cm} / \mathrm{sec}$, the slice of core will have to be very thin to achieve is reasonable flow rate; such a thin slice may not be very representative of the tuff on the C-well complex. The specific details of these experiments will be developed, if and when such core material is made available.

The tracers will be tested for mutagenicity using the Ames test. Ames testing uses specific strains of the bacterium Salmonella typhimurium selected for its inability to grow without the addition of a particular amino acid. When exposed to a mutagen, however, the selected bacterium reverts to wild type and can grow in the absence of the amino acid.

The quality assurance project plan (task 6) will be appended under existing DOE and USGS guidelines. The initial studies will include development of analytical protocols and set data quality objectives (DQOs) for future and ongoing work. Included will be the number of standard and reference samples. duplicates and spike samples, relative standard deviation between replicate analysis, chain of custody, and sample storage methods.

A final report (task 7) will be written that will address the suitability of each component tested as a tracer. Interim reports will be provided when significant findings for candidate tracers occur.

\subsubsection{Experimental Methods}

- Revisions are indicated by a vertical line in the right margin. 
Tracer.QAP

Revision No. $1^{*}$

Date: $12 / 13 / 93$

Page 31 of 38

\section{Batch Tests (task 3)}

Specific procedures covering the experimental methods are found in the project scientific notebooks, the Batch Test SOP, and the manufacturers' instructions for the instruments used to analyze for the individual tracers.

\section{Column Tests (task 4 )}

Specific procedures covering the experimental methods are found in the project scientific notebooks and the manufacturers' instructions for the instruments used to analyze for the individual tracers.

\section{Field Tests}

If field tests are conducted with any of the tracers tested under this project, a field test operating procedure will be prepared to cover the work. The timing and length of the field tests will also depend upon availability and location of a suitable site.

\subsubsection{Quantitative Objectives}

\subsubsection{Precision}

This study does not have a quantitative objective for precision. The chemical nature of the sample, the sample matrix, sample concentration, and the instruirent(s) used to make the measurement all affect the precision and, therefore, the precision tha is obtained with each compound during this study will vary. The actual precision obtained will be one of many factors considered when evaluating the suitability of each potential tracer. The measurement precision of each compound will be evaluated throughout the proposed research program without a criteria for data acceptance/rejection.

No corrective action will be taken based solely on the lack c $f$ precision or reproducibility. Corrective action, i.e., repeating the analysis, will be done based on the investigator's experience with the instrument, tracer, and sample matrix.

\subsubsection{Accuracy}

This study does not have a quantitative objective for accuracy. There are no traceable standards for the chemicals used for the batch and column experiments. Accuracy is therefore limited by the purity of the compound, the volumetric glassware, and the calibration of the balance. The study is concerned with changes in concentration over time affording a comparison with starting levels rather than true or reference values. The absolute concentrations are, therefore, not as important as the accurate description of these changes. The measurement accuracy of each compound will be evaluated throughout the study without a criteria for data acceptance/rejection.

\footnotetext{
Revisions are indicated by a vertical line in the right margin.
} 
Tracer.QAP

Revision No. $1^{*}$

Date: $12 / 13 / 93$

Page 32 of 38

\subsubsection{Completeness}

Completeness for the batch tests represents collecting data at scheduled intervals for a period of 60 days. If the tracer sorbs or is degraded before that time, data collection will stop for that potential tracer.

Completeness for the column tests is achieved when $85 \%$ of the introduced mass is recovered for a tracer that does not sorb or is not degraded. Tracers that sorb or are degraded will have smaller percentages of recovery, and the experiment will be terminated when, in the estimation of the project leader. no further useful data will be obtained.

\subsubsection{Qualitative Objectives}

\subsubsection{Representativeness}

Representativeness here concerns the conditions of the batch and column tests which are used to test the potential tracers. By using J-13 water, which is ground water from the general area of the $C$-well complex, and tuff from the area of the planned tracer tests, the chemical environment of the $C$-well aquifer will be closely approximated.

\subsection{CONTROL}

Activities performed for the Tracer Project are controlled by the technical procedures system for tasks that the project manager determines to be repetitive. Those tasks that require a high degree of judgement and/or are trial-and-error methods are controlled by the scientific notebook system.

\subsection{SCIENTIFIC NOTEBOOKS}

Scientific notebooks are prepared and used according to the HRC scientific notebook SOP. Scientific notebooks are used to record nonroutine tasks, results, and observations.

The project manager assures that each active scientific notebook is technically reviewed I monthly. The technical reviewer spot-checks calculations and checks that details are adequate to repeat the work and discusses observations and results. The HRC QA staff reviews active scientific notebooks quarterly for compliance to the SOP.

\subsection{STANDARD OPERATING PROCEDURES}

Standard operating procedures (SOPs) are composed to meet the technical procedures requirements of YMSCP QARD. These are used for routine tasks for which no deviation from the SOP is required.

\footnotetext{
- Revisions are indicated by a vertical line in the right margin.
} 
Tracer.QAP

Revision No. $1^{*}$

Date: $12 / 13 / 93$

Page 33 of 38

Scientific notebooks are used on the Tracer Project alternatively for purposes of recording or controlling details of those procedures which are not defined as routine.

\subsection{FACILITIES, EQLIPMENT, AND SERVICES}

All analytical chemistry work will be performed at the UNLV - HRC chemistry laboratory (with the possible exception of analysis of some samples from the field tests that will be done in the field). This laboratory is equipped with the chemical instrumentation and equipment necessary to perform the analyses for the tracers.

The location of field activities, if any, has not as yet been specified. Field activities may require climate controlled spaces with appropriate power to operate the analytical chemistry instrumentation and peripheral equipment.

Performing the batch and column tests will require routine laboratory equipment such as balances, volumetric glassware. pipettes, etc., as well as sophisticated analytical instruments such as high performance liquid chromatographs (HPLC) with ultraviolet UV) and fluorescence detectors and an HPLC-mass spectrometer (HPLC-MS).

\subsubsection{Manual data collection}

Manually collected data such as reintegrated peaks, ancillary data such as standards preparation. wet chemistry, observations, and other data are collected in the applicable scientific notebooks or on the associated chromatograms or other hardcopy. Any further reduction will be accomplished with an explanation of the method used (such as f'ormulae).

\subsubsection{Automated data collection}

Computer-generated data is collected as described in the associated instrument or software manual provided by the manufacturer. Any further reduction of the data, such as for calculating final concentrations, outlier determinations, subtracting blank levels, and other reduction procedures, are described in the applicable SOP or scientific notebook or on the associated chromatograms or other hardcopy.

\subsubsection{Standards}

Standards at three or more concentration levels will be used to generate a calibration curve from which tracer levels measured in test solutions will be quantitated.

\subsubsection{Samples}

- Revisions are indicated by a vertical line in the right margin. 
Tracer test solutions will be measured in triplicate. Data will be collected as described previously. The mean and percent relative standard deviation of the replicate measurements will be recorded in the scientific notebook.

\subsubsection{Data Reduction Procedures}

As described previously. procedures for the reduction of data are specified in the SOP or scientific notebook.

\subsubsection{Reporting}

Data is collected and reduced by the chemists and summarized for the project manager. Preparation of external reports is assured by the project manager. These include interim reports and quarterly reports as well as other types of reports.

\subsubsection{Flowchart of the data handling process (Figure 3.)}

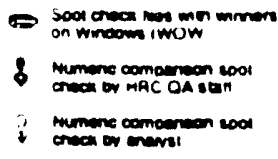

DATA REPORTING FLOW CHART

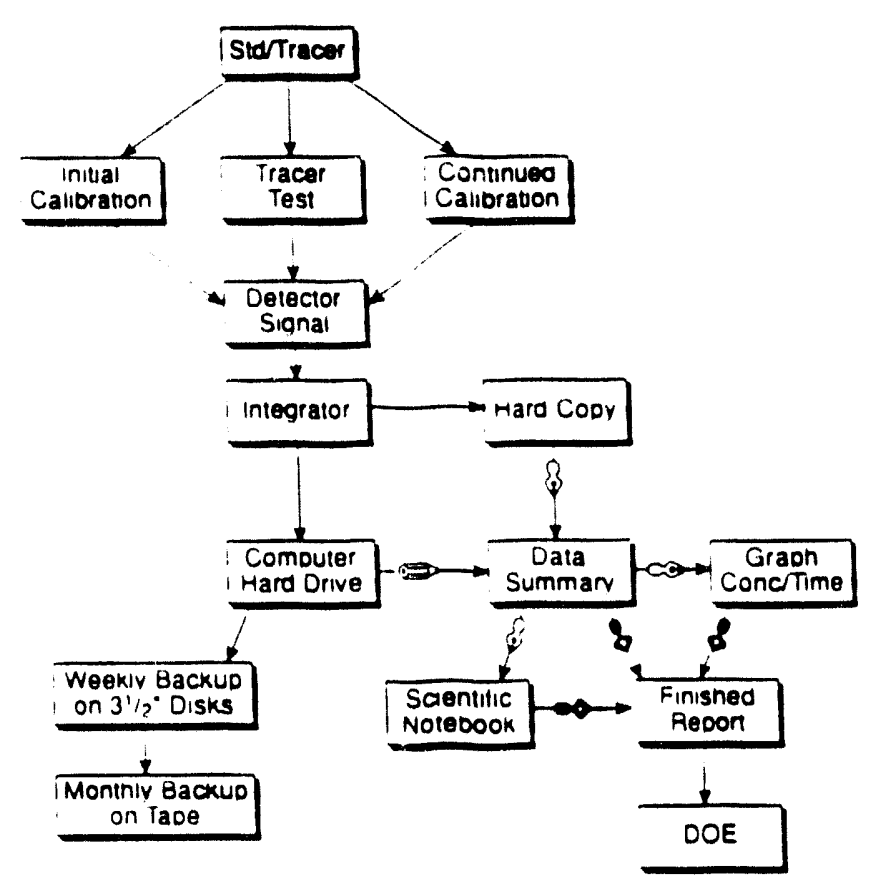

Figure 3. Flowchart of the data handling process. 
Tracer.QAP

Revision No. $1^{*}$

Date: $12 / 13 / 93$

Page 35 of 38

\subsection{DATA QUALITY ASSESSMENT AND VALIDATION}

\subsubsection{Precision}

As stated previously, precision is not one of the quality objectives. Please read 20.1.2.1.

\subsubsection{Accuracy}

Stock standard solutions containing each of the test tracers in both DI and J13 waters, will be used to prepare the samples. The stock standards in DI water will also be used to prepare the calibration standards to be used throughout the batch test. The following equation will be used to assess the stability of the standards concentrations over the course of the study. (One concentration level will be selected to represent each analysis set.)

$$
\begin{aligned}
\left(\left(A_{0}-A\right) / A_{0}\right) \times 100 \\
A_{0}=\text { original area counts } \\
A=\text { current area counts }
\end{aligned}
$$

where $A=$ peak area and $A_{0}=$ peak area for the initial calibration at $T_{0}$. If a value of $10 \%$ or greater occurs, a new standard will be prepared to determine if this is due to a change in the instrumental conditions or if the concentration of the standard has artually changed. If the concentration has in fact changed, new standards will be prepared. Also, the correlation coefficient for the standard curve must be equal to or exceed, the value given in the SOP in order to continue.

The use and preparation of a new calibration standard will be documented in the scientific note book. The equation above will be used, by substituting response factors (concentration/peak area) for peak areas.

The stock standards, in DI and J13 waters excluding tuff, w:ll be stored in sample jars and used as controls to determine the effect of tuff exposure on the tracers.

\subsubsection{Completeness}

Batch test data collection is scheduled at intervals for a period of 60 days. If the tracer sorbs or is degraded before that time, completion is achieved and data collection will stop for thá , Jtential tracer.

For the column tests data collection ceases and completeness is achieved when $85 \%$ of the introduced mass is recovered for a tracer that does not sorb or is not degraded. Tracers that sorb or are degraded will have smaller percentages of recovery, and the experiment will be terminated when, in the estimation of the project leader, no further useful data will be obtained.

\subsubsection{Vefification and Validation}


Manual calculations and area counts of standards will also be spot-checked routinely for errors and other indications of problems by the laboratory staff and the project manager.

Laboratory notebooks will be spot-checked and initialled by the HRC QA staff on a quarterly basis using the checksheet in the SOP. The project staff evaluate data as it is being generated and reported for its usefulness and value to the objectives of the study. Validity is evaluated based on the objectives of the study and, as basic research often is, using the background and professional judgement of the investigators. Valid data will be used to produce reports contributing to the resolution of the hypothesis.

20.7.4.1 Replicate analyses

Evaluation of replicate analyses contribute to the determination of data validity although there is no specific criteria for acceptance/rejection of data. Triplicate sample data will be analyzed for precision using the $\%$ RSD.

The procedures for data quality assessment are to be described in the SOP.

Outliers

Outliers are defined as data points that reside on the extreme limits of the bell curve or are unexpectedly high or low measurements. Data may be reviewed for outliers using one of the methods in "Quality Assurance of Chemical Measurements" by John K. Taylor, Lewis Publishers, 1987. pages 33-36. Outlier determinations may contribute to the validation of tracer study data.

\subsection{IDENTIFICATION AND CONTROL OF SAMPLES AND DATA}

\subsubsection{Sample Collection}

20.8.1.1 Tuff

Tuff used in the batch tests will come from outcroppings in the Yucca Mountain vicinity of the formation in which the C-well tracer tests will be conducted. Determination of where these materials are collected is made by the U.S. DOE or participant geologists. Samples are collected by DOE, HRC research personnel, and/or other participants. HRC will observe and perform property removal requirements and Yucca Mountain access regulations.

The core material for the column tests is obtained by the project manager's written request to the director of the Yucca Mountain Project (YMSCP) sample management facility. The origin of the core may be other than the C-wells, but will be from formations that are the same or similar to the ones in which the C-weils tracer tests will be conducted.

\subsubsection{Water}


Two types of water may he used for the batch and column tests. J-13 well water is obtained from the Nevada Test Site (NTS) with DOE and NTS authorization for collection. This water is then stored in the UNLV-HRC cold-room at $4 . \mathrm{C}$ in plastic containers.

Distilled water can be obtained from a variety of sources and should have a resistance greater than one megaohm.

\subsubsection{Laboratory Samples}

Samples for the batch and column tests will be collected according to general good laboratory practices as recorded in scientific notebooks.

\subsubsection{Identification}

Raw material samples are labelled with the date and geogranhic location of sampling.

In order to insure that samples are identified and controlled in a manner consistent with their intended use, all sample labels shall include the following identification (or code reference) once the material is introduced into an experimental phase:

Sample identification: type and sequence number ( $\because$ necessary)

Date of collection

Collection site

This information shall follow data in all of its forms, excluding formal reports, sufficiently to provide traceability among the data, analytical, wet preparation, and other components of the project data.

\subsection{SCIENTIFIC INVESTIGATION RESULTS}

Final results and a summary of the outcome or conclusions of the Tracer Project will be presented in a report to the YMSCPO.

\subsection{SAMPLE AND DATA STORAGE AND RETRIEVABILITY}

\subsubsection{Sample Handling and Storage}

Samples will be handled, stored, and labelled in accordance with the provisions of this document. All samples will be maintained in the laboratory and during transportation under conditions appropriate to the experimental and analytical conditions. Samples shall not be stored in an area that contains samples or reagents of high concentration which may cause contamination of the samples. 
Tracer.QAP

Revision No. $1^{*}$

Date: $12 / 13 / 93$

Page 38 of 38

20.10 .2

Sample Control

At each sample process step, wet chemistry, analysis, etc., the information contained on the sample label will be useu to identify associated data. extracts, etc.

20.10 .3

\section{Sample Curation}

After completion of the experiment, residual sample volume will be curated until it is determined that no analyses need to be repeated. Samples will be curated for no longer than three years.

\subsubsection{Sample Records}

A record of all samples. associated identification numbers. and circumstances of collection and handling are recorded in a scientific notebook entitled DOE Tracer Project.

\subsubsection{Data Handling and Storage}

HRC QA Policy requires that a copy of all project deliverables be stored in the Cooperative Agreement Files located in the HRC office and in the chemistry data management system. During the project. data may reside in the offices and files of project personnel.

Upon termination of the project, the data will be submitted to the QA officer and properly filed and/or distributed.

20.10 .6

\section{Data Transter}

The transfer of data from this study to other YMSCP researchers will be authorized by the project manager on a case-by-case basis. Only photocopies or computer copies will be authorized for transfer prior to the end of the study.

\section{Data Control}

For the purpose of this study, there are no controls for security purposes. The only other control is that Dr. Stetzenbach authorizes data release for proper intended uses. Prior to completion of the project. data shall not be released without the approval of the project manager.

\section{$20.108 \quad$ Data Curation}

All data produced and/or processed by the HRC for this study will be maintained in files for a minimum of three years from the termination of the project. 
Batch.sop

Revision: 0

Date: $12 / 27 / 93$

Page: 1 of 4

\author{
Harry Reid Center for Environmental Studies (HRC) \\ Standard Operating Procedure (SOP) \\ for \\ YMSCP Organic Tracer Project \\ Batch Test Procedure
}

NOTICE: This procedure is intended as a guide and reference to personnel on this project. Personnel are selected based on qualifications and are trained adequately to allow creative deviations, provided such deviations are recorded in the scientific notebook. Since this is a research project in which changes are inherent, deviations are expected.

1. Approvals:

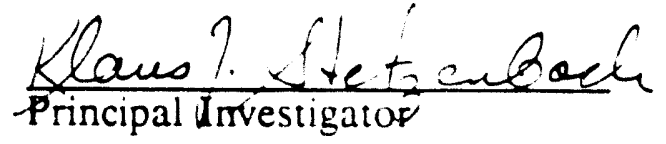

$\frac{10 \tan 94}{\text { Approvil Date }}$
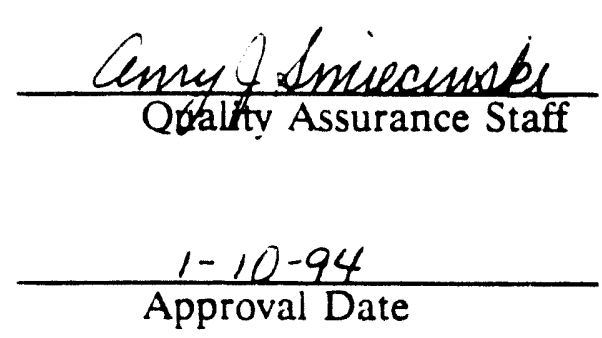

2. General Information

2.1 The batch test is designed to measure the stabili $\mathrm{y}$ of the candidate tracers in an environment that closely approximates the $\dot{C}$-well complex. These tests will be conducted with two water types and a number of water and soil mixtures. Distilled water will he used for control purposes and J-13 well water will be used to simulate the $C$-well water. The soils will be made up of crushed tuff from outcroppings of tuff in the area of the tracer tests. Three types of tuff will be used. These are referred to as light, medium and dark tuff due to their appearance.

2.2 Portions of each sample will be taken periodically and analyzed to determine if the concentration has changed.

2.3 To be considered as a viable tracer for this project, the compound must remain stable over a period of 60 days in all three tuffs and $\mathrm{J} 13$ water.

3. Instrumentation:

3.1 Spectra Physics, SP8800 Ternary HPLC Pump Spectra Physics, SP8880 Autosampler 
Spectra Phisics, Spectra 100 Variable Wavelength UV/Vis Detector Spectra Physics. Winners on Windows Software Spectrovision, FD-200 variable wavelength Fluorescence Detector.

\section{Analvtical Methods:}

4.1 No approved analytical method is available for these compounds. The instrument conditions such as eluting solvent, detector wavelengths, and solvent conditions are dependant on each particular analyte and will therefore vary throughout each individual batch test. The analytical conditions will be documented in the scientific notebook.

5. Instrumental Start-up

5.1 Instrument start-up will be performed according to the instructions listed in the Instrument SOP.

6. Calibration

6.1 Three or more point calibration is performed daily during sample analysis.

6.2 The concentration of the calibration standards will be selected so that they bracket those of the samples.

6.3 Correlation coefficients for calibration curves will be equal to or exceed 0.95 or corrective action will take place.

6.4 A mid range standard will be analyzed after every 10 samples. The response for this check standard must be within $10 \%$ of that obtained from the initial calibration or corrective action will take place.

7. Sample Preparation

7.1 Three types of tuff (dark, medium, and light) a:ıd two types of water (deionized and J-13 well water) will be used to evaluate each tracer for a total of 6 samples analyzed per tracer.

7.2 Stock solutions, containing each o: the potential tracers in deionized and $\mathrm{J}$ 13 water will be prepared. Solutiuns preparation will be documented in the scientific notebook.

7.3 Approximately $250 \mathrm{~g}$ of each tuff are added to $500 \mathrm{~mL}$ amber or foil wrapped glass bottles with teflon lined screw tops.

7.4 The stock solutions are added to the bottles containing tuff to make an approximately $1: 1 \mathrm{w} / \mathrm{w}$ mixture. The bottle is well shaken to assure that all the tuff comes in contact with the tracer solution.

7.5 Approximately $2 \mathrm{~mL}$ of the water portion from each sample are analyzed periodically over the 60 days at approximately $T=0,1,5,10,20,30$, and 60 days. If any solid material is observed in the water, the sample will be filtered using a Millipore syringe filter. 
7.6 Blanks are prepared which contain each of the tuffs in both waters, but no tracer.

7.7 Control samples are prepared which contain tracer solution in deionized and in J-13 well water but no tuff.

8. Quality Cuntrol

8.1 The blanks described in sec 6.6 will be analyzed prior to calibration. These serve two functions: 1) to assure that the reagent water is in control and 2) as the batch test progresses, the blank will be used to detect changes in the sample which are not related to the tracer.

8.2 A minimum of $10{ }^{\circ} \circ$ of the samples will be run in duplicate.

8.3 Correlation coetficients for calibration curves will be equal to or exceed 0.95 or new calibration standards will be prepared.

8.4 The calibration standards will be prepared from the same stock solution as the samples (in deionized water only). These calibration standards will be used throughout the entire study, if possible. The average response for one concentration level will be monitored throughout the study; the average area must be within $10 \%$ of that obtained at $T_{0}$ or corrective action will take place.

8.5 The chromatographic conditions will remain constant throughout the study unless some unforeseen difficulty arises that interferes with the quality of the data (i.e., a coeluting peak develops over the course of the study). If the conditions are changed, then the standards will be checked under the old conditions. The standards for the subsequent analyses will be tested against those used once the conditions were changed.

8.6 A mid range standard will be ran after every 10 samples. The response for this check standard must be within $10 \%$ of that obtained from the initial calibration or corrective action will take place.

9. Record Keeping

9.1 An instrument logbook will be kept to record all pertinent information including (but not limited to): analyst ID, standards and sample preparation, instrument maintenance, and any deviations from the standard operating procedure.

9.2 The logbook will be kept in accordance with the standard laboratory notebook/logbook guidelines and procedures laid out in the HRC Notebook SOP.

9.3 Hard copies of all analyses will be filed (currently in room 167A and B) referenced by analytes and time of study, with $T_{0}$ as the first day of the study.

9.4 Data will be saved on $31 / 2$ inch disks, referenced by the date of analysis. 
Batch.sop

Revision: 0

Date: $12 / 27 / 93$

Page: 4 of 4

This will be documented in the laboratory notebook.

9.5 The computer hard drive will be backed up monthly.

10. Calculations and Data Manipulation

10.1 The Winners on Windows software and/or a software spreadsheet program such as Lotus 123 or Quattro Pro will be used for regression analysis, and the calculation of mean and \% RSD values. The procedure used will be documented in the scientific notebook. Calibration using Winners on Windows software is explained in the SOP.

10.2 Regression analysis will be achieved using peak areas as the dependant variables and concentrations as the independent variables. If calibration standards are run in triplicate, the average peak areas will be used as the dependent variables.

10.3 Concentration vs. time will be graphed for each tracer in each of the tuffs. Each graph will contain a plot of the control as well as the tracer in a given tuff. 
Notebook.sop

Revision: 1

Date: $3 / 31 / 93$

Page 1 of 8

Harry Reid Center for Environmental Studies (HRC)

Standard Operating Procedure (SOP)

\section{SCIENTIFIC NOTEBOOKS}

1.0 Approvals

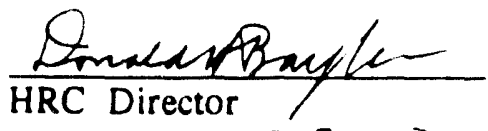

Approval date: $3-31-93$
Amy tumecuster

Quality Alsurance Staff

Approval date: $3-31-93$

\subsection{Distribution}

Revisions of this document are distributed by HRC Quality Assurance (QA) Staff to each Principal Investigator (PI) having a project in the laboratory.

\subsection{Control}

Each PI provides project personnel with a copy of the most current version of the document. The HRC QA Staff keeps a list of PIs receiving SOPs to assure that each PI has the most current version.

\subsection{Purpose}

This SOP describes procedures for the use and maintenance of HRC scientific notebooks and establishes guidelines for recording and preserving data. This serves:

- To record and preserve research, development, expe: mental, test, and evaluation data.

- To provide a convenient reference for s:ientists to use in the performance of current and future work.

- To provide a complete and permanent record to assure the continuity of effort in the event of transfer, termination, illness, etc. of an employee.

- To preserve for legal purposes all data describing the work performed.

\subsection{Scope}

This SOP addresses the use of scientific notebooks in laboratory studies. QA plans may supercede requirements of this procedure to meet the needs of the project.

'Revisions to this document are indicated in italices. 
Notebook.sop

Revision: 1

Date: $3 / 31 / 93$

Page 2 of 8

\subsection{Responsibilities}

Group supervisors are responsible for seeing that individuals in their work groups: 1) use proper recordkeeping procedures; and 2) record data in a timely manner. Evidence of notebook reviews by supervisors is to be documented in each sciensific notebook periodically (at least quarterly). A laboratory notebook assessment plate is attached to aid in the review process.

The QA ofticer (QAO) is responsible for determining if laboratory notebook policies are in place and that associated SOPs are updated on a regular basis. The QA officer assesses the scientific notebooks semiannually using the attached plate. Assessment results with suggested corrective action are reported (o) the associated PI. Unresolved defects are reported to the HRC Director.

\subsection{Acceptable Recordkeeping Practices}

Laboratory personnel will use laboratory notebooks to record pertinent information in a timely fashion on research, development, test and evaluation activities, and production tasks. In addition, information from conferences, laboratories, and agencies pertinent to the project shall be included in the scientific notebooks.

Laboratory notebooks will be maintained in accordance with the procedures described below. This policy is not intended to restrict the use of additional records provided the laboratory notebook references the additional records.

Please keep in mind also that procedures can be referenced by document or page number rather than rewritten in the notebook each time they are performed.

Pages must not be removed from any notebook.

Ink (preferably black) only is to be used in notebooks.

White-out is not to be used in the scientific notebooks.

No notation is to be completely obliterated. A single line-through, with initials and date of the change are acceptable.

Notations are to be legible and understandable.

Loose papers and forms may be permanently affixed to a page of the scientific notebook provided the margin of the attachment is initialled and dated across the insert edge and notebook page.

If there is a continuation of work from other notebooks or to othit notebooks, reference

'Revisions to this document are indicated in italices. 
Notebook.sop

Revision: 1

Date: $3 / 31 / 93$

Page 3 of 8

these numbers in each notebook (i.e., "continued in..." and "continued from...").

Record data and observations in a timely manner: carry the scientific notebook with you as you perform the work (unless this is hazardous) and record steps, data, etc., as it occurs. This will often help a scientist catch his own error.

If a large blank space remains on a notebook page that the scientist does not intend to use prior to the next record, line-through the space and initial and date it.

Sign and date the bottom of each completed page and the conclusion of each separate entry.

The name of the scientific notebook, other identifiers, and the lab name is to be written on the cover.

Omitted data or appended data is to be recorded on the tirst available page with the date of addition and reference to the appropriate notebook page. Reference to the anpended data should be noted and dated at the page it applies to as well.

All hardbound scientific notebooks will be inspected and signed at least quarterly by a supervisor or the lab director, and semiannually by the QAO. The attached assessment plate may be used when inspecting notebooks. Written comments concerning the maintenance of the notebook are to be made in the notebook. The employee is to take immediate corrective actions on deficiencies noted during an inspection or audit. (Note: This does not mean altering previous data or inserting outdated data. Any changes that are made to previous records should be initialled and dated to reflect the date that the corrective action is being taken. Omitted data should be added on the first available page with the date of addition as described previously.)

\subsection{Disposition}

Laboratory notebooks are to be kept for a period of at least three years after completion of the last project covered by the notebook, or when it is no longer needed for reference purposes, or superseded by the client's policy, whichever is later. Notebooks will not be disposed of unless approved by the HRC director after written direction from the client.

\subsection{General Guidance}

The following descriptions serve as suggestions for types of information that should be included for each record category. Organization of the records within scientific notebooks is decided by the scientists and PI based on the needs of the project. For example, for some research projects more than one of the categories described may be found in a notebook.

\section{Instrument Records}

'Revisions to this document are indicated in italices. 
Notebook.sop

Revision: 1

Date: $3 / 31 / 93$

Page 4 of 8

Instrument records should contain the types of information listed here as appropriate to the analytical system.

Instrument maintenance records include service records and repairs performed by HRC personnel and service representatives. It is important from a preventive maintenance standpoint that symptoms be recorded with the resulting repair for future troubleshooting.

Injection or "run" records contain documentation of every analysis, burn, calibration, standardization, etc, that is performed on the associated instrument. Information should be complete enough to allow duplication of the analysis, within the limits of the process, and show traceability from the original sample or standard to the raw and hardcopy data printout. Examples of pertinent information include injection volumes, column parameters, project name, repeat analyses due to rejected data. instrument conditions, sample control numbers (such as case numbers), analyst name or initials. instrument conditions, computer programs used to process data, etc.

Tape notebooks serve as a reference tool to indicate which tape project analytical data is stored on and when.

\section{Extraction Records}

Information that is documented for extractions includes a step-by-step description or reference to the processing of each sample or aliquot that is extracted. This may be accomplished with the use of a checksheet that is attached to the scientific notebook using the procedure described in Section 3. Critical information includes lot numbers of any standards or spikes that are used, sample control numbers, extraction chemist name or initials, project name, observations, reagent lots, etc.

\section{Digestion Records}

Digestion records include the same type of information listed for Extraction records.

\section{Standards Preparation}

All information concerning the preparation, dilution, transfer, etc., of standards and spikes is to be recorded in the standards preparation records. It is required that these solutions be traceable to their original source and to any resulting data. Therefore lot numbers and any other identifications must be included in the associated scientific notebook entries.

It is highly recommended that all standard and spike preparation and dilution calculations be doublechecked by a coworker as a quality control measure to insure accuracy of the preparation and prevent human error. Therefore, calculations should be presented in an equation format that will facilitate the review.

'Revisions to this document are indicated in italices. 
Notebook.sop

Revision: 1

Date: $3 / 31 / 93$

Page 5 of 8

\section{Sample Control}

Sample receipt records contain basic information that is critical to the project: the date and time of sample arrival, the sample conditions, the assigned storage area, the sample and analysis types, any associated identification names and numbers, chain-of-custody seals, shipping papers, and the sample numbers, etc.

\section{Project Records}

These scientific notebooks are highly project-specific for formatting and contents. However, certain basic information may be pertinent to any project:

Project names, project coordinators, client technical monitors, and other identitiers.

Associated document titles (work plans, task directives, literature, SOPs, standard procedures, etc.) used.

Detailed observations, variations from the original experimental design, problems, external influences on the project, thought processes and scientific notebook trees, and concerns of the chemist.

Statistical analyses, conclusions, and results.

Data from other scientific notebooks or references to other scientific notebooks, the contents of which may contribute to the project.

\section{Balance Accuracy and Precision}

Balance Accuracy and Precision scientific notebooks or log si.eets are generally maintained for the entire HRC lab rather than for each project. However, special needs of the project or client may require otherwise.

This scientific notebook or log is maintaines as stated in the associated SOP for this equipment. The record includes the dates of the checks, the identity of the weight set used, the initials of the personnel making the check, observations of malfunctions, and documentation of corrective actions and service as well as scheduled manufacturer calibrations.

\section{Laboratory Water System}

This recordis maintained in accordance with the requirements of the associated SOP for this QC check. The scientific notebook or log contains the dates of the checks, the initials of the personnel making the check, pressure and conductivity readings, observations of malfunctions, and documentation of corrective actions and service.

'Revisions to this document are indicated in italices. 
Notebook.sop

\section{Refrigerator Temperature}

This record is maintained in accordance with the requirements of the associated SOP for this QC check. The scientific notebook or log contains the dates of the checks, the initials of the personnel making the check. thermometer readings, observations of malfunctions, and documentation of corrective actions and service.

\section{Eume Hood Flows}

This record is maintained in accordance with the requirements of the associated SOP for this QC check. The scientific notebook or log contains the dates of the checks, the initials of the personnel making the check. flow readings, observations of malfunctions, and documentation of corrective actions and service.

\section{Software Verification}

This scientific notebook contains the software/version being tested, who tested it on what date, and a nutation of any problems or special code used in the verification/validation. Finally, a signature shows that the soriware wi successfully tested and approved for use.

'Revisions to this document are indicated in italices. 
HRC Lab Scientific Notebook Assessment Plate

Notebook Title:

User:

Yes No Comment

1. Is a numbered, hardbound, with pre-printed consecutively numbered pages scientific notebook in use?

2. Using this notebook. is it possible to trace from it to the other pieces of the project that it represents?

3. If this notebook consains standards preparation, is it possible to trace from the raw data it represents to the original standard material. using this notebook?

4. Is the front of the lab notebook labeled with the notebook name?

5. If there is a continuation of work from or to another notebook, is this indicated in each scientific notebook?

6. Are the scientific notebook pages intact?

7. Is the notebook understandable?

8. Is the notebook legible?

9. Is the notebook up to date?

10. Are entries made in ink?

11. If rejected data are not documented in the scientific notebook, are they documented in the data report or on the raw data?

12. Does the notebook contain "white out"?

'Revisions to this document are indicated in italices. 
13. Are corrections made using a single line-through, with initials and date?

14. Are attachments or inserts permanently secured and signed across the margin and onto the scientific notebook page?

15. Is recorded information signed and dated by the notebook user at each entry (when >1 day's entries are recorded on a page) and at the bottom of each complete page?

16. Are blank entry areas invered with a line-through. initialled, and dated?

17. Has the supervisor or director reviewed the notebook within this quarter?

Numbered comments regarding checkpoints above:

Reviewer's signature:

Date:

'Revisions to this document are indicated in italices. 
DOE Tracer Project

Revision No. 0

Date: $04 / 02 / 92$

Page 1 of 2

YMSCP Organic Tracer Project

Standard Operating Procedure

\section{SARTORILS 2+32 A.VALYTICAL BALANCE}

Standard procedures wil be covered in two sections. actual balance operation and calibration theck procedures.

\section{BALANCE OPERATION}

1. CHECK ZERO: Set ald controls to zero. Turn release lever (left side. behind weight dial) down to the "0" position. If scale does not stop on zero. adjust with the zero control knob (right ide. behind micrometer controll.

2. WEIGHING AN LINKNOWN: Place object on pan. Close balance doors and turn release lever to " $1 / 2$ " position. Dial in weights. starting with the lic rgest series. When too much weight is added, the scale moyes below zero; go back one step (if 30 is too much. go back to 20). Then use the next lower series.

3. READING THE RESULT: When all the weights have been used. turn the release lever down to the " 1 " position. When the scale stops, use the microneter knob to superimpose the pointer on the next lower division. Read the total weight from let. to right observing the decimal point.

4. MLKE ALL ADJUSTMENTS SMOOTHLY: Stop momentarily in the full arrest ("0" position, before moving the release lever to full release (" 1 " position). If pan swings too much. irrest once more.

\section{NEVER DLAL IVEIGHTS IN FULL RELEASE POSITION}

CALIBRATION CHECK PROCEDURES: Everyone using the balance must observe the following procedures.

1. LOGBOOK ENTRIES: All log book entries must be dated and initialed or signed by the person making the entry. A brief description of the substance weighed should be entered on the appropriate line (example: Potassium Phosphate crystals).

2. STANDARD WEIGHTS: The two (2) gram weight from the PERMAS Standard weight set should be weighed as a calibration check before and after each sample.

3. WEIGHING PROCEDURE: When an object or substance is to be weighed. first weigh the standard two (2) gram weight and record this value in the appropriate column in the log book. 
DOE Tracer Project

Revision No. 0

Date: $14 / 02 / 92$

Page 2 of 2

Rezero the balance. then welun ine samole. according to the directions outlined above. Enter this llue. diong with a briet vexcration or the sample. into the log book. Rezero the balance and then Ewelgh the two (2) gram xelunt. Record this value in the log book. Sign or initial the logbook - elow your entries. and cneck to ne sure inat the date is recorced correctly. Reset all weignt values :o zero. and piace the retease : e'er in the arrested or "1)" position betore leaving the balance. 

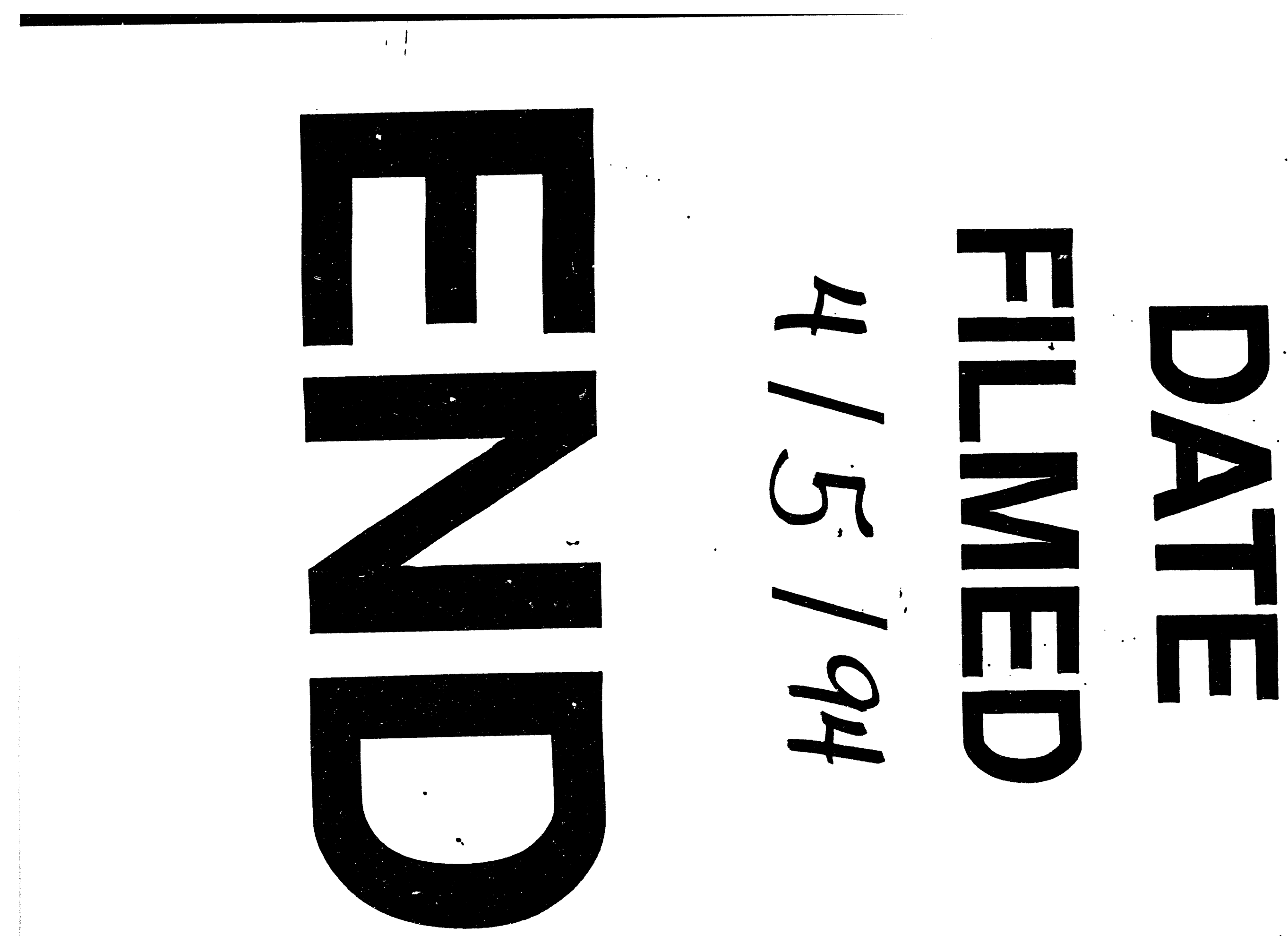
